\title{
CÁDIZ Y LA ISLA DE CUBA EN LOS INICIOS DEL SIGLO XIX
}

\author{
Gloria de los Ángeles Zarza Rondón
}

\section{RESUMEN}

Al menos hasta 1765, el puerto gaditano capitanearía la carrera de Indias, y por tanto llevará las riendas del sistema monopolístico comercial. Con todo ello, Cádiz seguiría un crecimiento continuado de su población, con una numerosa presencia de contingente europeo y americano durante el siglo XVIII. No obstante, la situación se modificaría durante el siglo XIX, cuando las circunstancias políticas y civiles, a uno y otro lado del Atlántico, dejen de favorecer la supremacía comercial de la ciudad gaditana, y por tanto el flujo de emigrantes se reduzca considerablemente. Las medidas tomadas durante las décadas 20 y 30, reactivarían la vida comercial y mercantil de la ciudad, y reflejo de ello, serán las cifras regularmente continuadas de emigrantes cubanos registrados en el Archivo Histórico Municipal, que hagan de Cádiz su lugar de residencia durante la primera mitad del siglo XIX.

Palabras Clave: Sistema monopolístico, siglo XIX, padrones, emigrantes, comercio, sector terciario, servicio doméstico, mano de obra esclava, individuos libres, cabezas de familia, negocios, rentas, militares

\section{ABSTRACTS}

At least until 1765, the gaditan port commanded the race of Indians, and therefore to take the reins of commercial the monopolistic system. Yet it, Cadiz will continue a growth continued of his population, with a numerous presence of European and American contingent during century XVIII. However, situation was modified during century XIX, when the policies circumstances and civil, on both sides of the Atlantic, they let favours the commercial supremacy of the gaditan city, and therefore the flow of emigrants is reduced considerably. The measures taken during decades 20 and 30, reactivated the commercial and mercantile life of the city, and reflection of it, will be the regularly continued numbers of registered Cuban emigrants in Municipal the Historical File, who make of Cadiz their place of residence during first half of century XIX.

Key Words: Monopolistic system, ninetheen century, register, emigrants, commerce, terciary sector, domestic servant, slaved work, free indivuals, head of household, business, rents, military 
En el ámbito académico en general, y en el histórico en particular, son numerosos los trabajos e investigaciones realizados acerca de las relaciones comerciales y humanas entre España y el Continente americano.

Encontramos todo un abanico de posibilidades en la historiografía consultada sobre esta línea temática, y en la manera que el asunto se centra en las relaciones entre la ciudad de Cádiz y los territorios ultramarinos, dichos trabajos se multiplican en su dimensión comercial y mercantil en cuanto a los siglos XVII y XVIII se refiere.

No obstante, y tras mucho contrastar y analizar, hemos hallado un considerable vacío historiográfico en las relaciones entre la ciudad gaditana y la Isla de Cuba en la primera mitad del siglo XIX. A partir de aquí, nuestro principal objetivo ha sido el de intentar rescatar todos aquellos datos y documentos que pudiesen revelarnos cualquier tipo de información acerca de la vinculación mercantil y humana, fundamentalmente el aspecto humano, que está ampliamente significado en los padrones que obran en los fondos documentales del Archivo Municipal de la ciudad de Cádiz. Curiosamente, hasta ahora, poco o nada se ha investigado sobre los mismos, pese a ser una fuente rica en detalles y de fácil consulta.

En los referidos fondos documentales, se establece la llegada continua, aunque pausada, de migrantes americanos que siguen haciendo de la ciudad de Cádiz, no sólo su lugar de desembarque, sino también de residencia.

Por esto, hemos pretendido a lo largo de nuestro trabajo de investigación mostrar sintéticamente, la presencia del considerable contingente de población cubana en nuestra ciudad. Así hemos tratado de constatar el número de personas procedentes de la Isla de Cuba, fundamentalmente de la ciudad de La Habana, los oficios desempeñados una vez llegados a la ciudad, el recibimiento social y profesional que encontraban al desembarcar, las posibilidades de prosperidad con que contaban, las razones que les empujaban a cruzar el Atlántico, la tipología de migrante cubano en función del sexo, edad, oficio, nivel socio-económico, profesional, continuidad de relaciones mercantiles y la presencia de comerciantes cubanos en la ciudad. Resumiendo: el tipo de vida y el rol que iba a desempeñar este grupo en el Cádiz de la primera mitad del siglo XIX.

Los resultados iniciales, creemos, han sido ampliamente satisfactorios, y nos han abierto un camino aún sin explorar sobre esta vertiente de la historia común entre la ciudad gaditana y la Isla de Cuba.

Como botón de muestra, hemos querido ofrecer un pequeño ejemplo de la continuidad de estas relaciones a través del análisis de las diferentes series de padrones del Archivo Histórico Municipal, y que se ofrecen al final de este artículo, pretendiendo adelantar una investigación mucho más exhaustiva, que vendría a significar una nueva página acerca de la vinculación directa entre ambas orillas del Atlántico.

\section{del XIX \\ 1. Apuntes históricos sobre Cádiz y Cuba entre dos centurias: finales del XVIII y comienzos}

El 12 de octubre de 1778, se declaró la Ley del libre comercio entre España y América. Parece a primera vista que este cambio sería tremendamente perjudicial para la ciudad de Cádiz, que hasta entonces, centraba en su puerto el monopolio del comercio con las Indias; pero no fue así (al menos durante el último tercio del siglo XVIII).

Indudablemente, Cádiz se había beneficiado hasta ahora más que el resto de puertos españoles de los contactos mercantiles y humanos transoceánicos.

Como ya es sabido, en el siglo XVIII, España no estuvo bajo ningún concepto dispuesta a compartir, y mucho menos renunciar, a los derechos adquiridos sobre el Nuevo Mundo desde su conquista, por lo que pondría en práctica una política que diese mayor brío y vigor a la noción de imperio económico y comercial con América, eliminando la participación extranjera y estrechando lazos de dependencia económica entre la metrópoli y las colonias. Por tanto, al menos hasta 1765 el puerto gaditano capitaneó la Carrera de Indias y por tanto encabezó al sistema monopolístico comercial que la política borbónica tanto se había esmerado en reforzar y poner en práctica cuanto antes. 
De tal forma, a partir de esta concentración del tráfico colonial en el puerto de Cádiz (17171778), comenzaría para la ciudad una auténtica época de esplendor que se vería reflejada a lo largo y ancho de toda la trama urbanística, demográfica, social, económica y política de Cádiz. ${ }^{1}$

La ciudad gaditana se convertiría en el punto de partida y regreso obligatorio de todos los viajes ultramarinos, siendo el principal centro de gravedad del comercio hispanoamericano, es decir, el único puerto del litoral español habilitado para comerciar directamente con los dominios ultramarinos.

Cabe destacar, que para que todas estas circunstancias se llevasen a cabo, hubieron de confluir una serie de características que, casi en exclusividad, la ciudad de Cádiz podía ofrecer, no solo por su emplazamiento físico y geográfico, sino porque desde mucho antes del descubrimiento del Nuevo Mundo funcionó como centro de operaciones mercantiles y financieras, legales e ilegales para los marinos y corsarios de la Andalucía atlántica y el Algarbe portugués.

Producto de esta tradición milenaria que hacía de Cádiz una ciudad habituada e imbuida en la compleja estructura de las redes comerciales y mercantiles, lo constituiría el binomio "población- comercio" que siempre mantuvo desde sus orígenes. Durante los siglos XVII y XVIII (aunque con algunas variaciones derivadas de la situación política del país), Cádiz seguiría un crecimiento continuado de su población. Entradas y salidas de emigrantes, establecimientos de casas de comercio, llegada de comerciantes de toda Europa y también de América, constituían el quehacer cotidiano en el Cádiz del siglo XVIII. ${ }^{2}$

De tal forma, y tal como afirma el profesor Manuel Bustos en su obra: Cádiz y el Atlántico. La ciudad, sus comerciantes y la actividad mercantil (1650-1830): "Comenzaría para la ciudad una auténtica época de esplendor que se vería reflejada a lo largo y ancho de toda la trama urbanística, demográfica, social, económica y política de Cádiz.". ${ }^{3}$

Sin lugar a dudas podemos afirmar que "lo que atraía ese flujo continuo de personas a la bahía era su actividad mercantil y comercial que en Cádiz se efectuaba de forma sostenida, así como las múltiples oportunidades que de ella se derivaban. La gente venía a "buscarse la vida, lo que daría lugar a otra de las características fundamentales de la sociedad gaditana: la presencia estructural de una importante población llegada de fuera de la provincia, de Andalucía, de España, de Europa, y como no, de América". ${ }^{4}$

Como vemos, por su condición de puerto monopolístico, se convertirá en un enclave receptor del contingente extranjero (y nos referimos también al americano) numeroso y potencialmente activo, que además de condicionar la vida en la ciudad, le proporciona un aire cosmopolita. En este sentido, Cádiz, como señala Rafael María de Labra: "por la templanza de su clima, por la dulzura de su habla, por buena parte de sus gustos y sus costumbres, por la suavidad de sus maneras y la presencia y comunicación frecuente e íntima de peninsulares y americanos, es una porción de América puesta dentro de España."

Sus calles y plazas eran, materialmente, "el punto céntrico y principal escenario de la vida hispanoamericana". La ciudad cuenta con una población americana estable, y el gaditano llega a vincularse, en muchas ocasiones, familiarmente con esta población de ultramar.

Tal es la situación, que la continuada oleada de inmigrantes, generaba, a su vez, un claro efecto de cosmopolitismo, multiplicidad lingüística y hasta étnico-religiosa en la ciudad, debido como veremos a la presencia de esclavos, negros o mulatos procedentes de América.

De este modo, vemos como el comercio colonial conoció en la ciudad de Cádiz un crecimiento sin precedentes a lo largo de la mayor parte del siglo XVIII, resultado en última instancia del aumento de la demanda, o lo que es lo mismo, del incremento general de la población de una parte y del consumo de

FERNÁNDEZ MAYO, Manuela: El impacto del comercio americano sobre la estructura demográfica, social y urbana de Cádiz a mediados del siglo XVIII . Cádiz. Universidad de Cádiz. 2004. En la obra puede verse magníficamente reflejado el entramado social y político del Cádiz del XVIII y como la actividad mercantil y comercial con las colonias americanas influye de manera determinante en la ciudad.

2 GARCÍA BAQUERO-GONZÁLEZ, Antonio: Cádiz y el Atlántico, 1717- 1778. El comercio colonial español bajo el monopolio gaditano ( 2 tomos). Sevilla. Escuela de Estudios Hispanoamericanos. CSIC. 1976. Excelentísima Diputación Provincial de Cádiz.

BUSTOS RODRÍGUEZ, Manuel: Cádiz en el sistema Atlántico. La ciudad, sus comerciantes y la actividad mercantil (16501830). Cádiz .Servicio de Publicaciones de la Universidad de Cádiz. Silex Ediciones.. 2005. op. cit. pag. 37.

4 Ibídem. op. cit. pag. 73.

5 LABRA Y MARTÍNEZ, Rafael María de: América y la Constitución española de 1812. Madrid Tipografía Sindicato de Publicidad. 1914. 
bienes americanos y europeos en sectores todavía reducidos numéricamente, pero cada vez más amplios de la sociedad española, europea y criolla de la otra, animado todo ello por la mejora de su nivel de vida.

No obstante, los problemas no tardarían en llegar, sobre todo a raíz de la declaración de guerra de España a Gran Bretaña el 4 de octubre de 1796, y de la cadena de acontecimientos que de ella se derivaron, iniciándose así una crisis estructural en toda regla, y el bloqueo del puerto gaditano se alargaría hasta 1801.

A partir de aquí comienza la verdadera andadura de nuestra investigación; una vez inmersos en la nueva centuria (siglo XIX), las circunstancias dejan de favorecer a la ciudad de Cádiz, principalmente en su aspecto comercial y mercantil, no sólo con un bloqueo comercial que limitaba su actividad con Indias, sino también con un brote epidémico que causaría un total de 4766 muertes en la ciudad; y a esta difícil coyuntura local habría que sumar el inicio en la Península de la invasión de las tropas napoleónicas en 1808, y, al mismo tiempo, en América tienen lugar los primeros brotes independentistas desde 1809-1810. ${ }^{6}$

Por tanto, iniciamos el siglo, con una etapa depresiva y nefasta para el comercio hispanoamericano con una importante bajada de las exportaciones hacia el Nuevo Mundo.

Ante esta situación se hacían necesarias una serie de medidas que paliaran el desastre económico y social.

Tanto es así, que tomando como referencia la obra del profesor Ramón Solís: "El Cádiz de las Cortes. La vida en la ciudad en los años 1810- 1813", se nos dice lo siguiente: <<...Sin duda que cualquiera que sea el éxito de esta guerra y el destino de las Américas, los pueblos agricultores de la Península, que más o menos lo son todos, excepto Cádiz, podrán recuperarse, y aun mejorar infinito su estado, adelantando en agricultura o industria como podrán hacerlo quedándoles siempre los recursos que la naturaleza les concedió. Cádiz, por el contrario, sabe de cierto que su suerte ha de empeorarse siempre, arruinándose enteramente o decayendo hasta más o menos aproximarse a ello: lo primero si las Américas se separasen de nosotros, y lo segundo, con sólo decretarse libertad o franquicias de comercio de los extranjeros con ellas, pues siendo el de este puerto con las Américas el único apoyo de su subsistencia, destruyendo o aminorando dicho comercio, se destruye o se aminora irremediablemente la subsistencia del pueblo" $>>^{7}$

En cuanto a la emancipación de las colonias, estas van a provocar la definitiva caída del comercio gaditano, produciéndose una cadena de quiebras en numerosas casas comerciales que alcanzan en 1824 a 227 de las 623 existentes, y de 300 armadores tan sólo quedarían 20. La única solución parecía ser convertir a Cádiz en un Puerto Franco mediante un Real Decreto del 21 de febrero de 1829, en el que Fernando VII establecía de manera "definitiva" la franquicia del puerto de Cádiz. De este modo, las medidas tomadas reactivaron durante cierto tiempo el comercio, y reflejo de este tímido renacer del comercio gaditano serán las cifras más o menos continuadas de comerciantes y emigrantes americanos que comprobamos se trasladan a Cádiz durante la primera mitad del XIX. En definitiva, y como vemos reflejado en las listas de padrones analizados, la afluencia de americanos en Cádiz decae en comparación con los siglos precedentes pero no cesa, ya que la ciudad continuó siendo un referente singular en cuanto a metrópolis comercial se refiere.

Por otra parte, y continuando con el estado de la cuestión, describiremos de forma general la situación de la isla de Cuba a comienzos de esta nueva centuria, para así proceder a una comparación entre ambas partes y establecer las razones principales por las que a pesar de disminuir considerablemente el flujo migratorio desde la isla a la ciudad gaditana, éste no cesa a lo largo de todo el siglo XIX.

En los albores del siglo XIX, los dominios españoles de América quedaron reducidos a las Grandes Antillas, exceptuando la parte occidental de Santo Domingo (Haití).

En el caso cubano, las décadas anteriores a la independencia de América continental fueron un período de fuerte crecimiento, debido fundamentalmente a la expansión de la producción azucarera. Por tanto, los cambios administrativos y las medidas de fomento para que la colonia no generase gastos a España y contribuyese a engrosar su erario, solo incentivaron dicho crecimiento.

RAMOS SANTANA, Alberto : Cádiz en el siglo XIX. Vol. III. (4 Tomos). Madrid. Sílex Ediciones. 1992.

SOLÍS LLORENTE, Ramón: El Cádiz de las Cortes. La vida en la ciudad en los años de 1810 a 1813. Madrid. Plaza \& Janes S. A. Editores. 1978. p. 141. 
Así pues, en el inicio del siglo XIX, las economías de la Gran Antilla y Borinquen, incluso de Santo Domingo, eran similares en cuanto a dotación de recursos y potencialidad de crecimiento. Disponían de suelos fértiles, muy adecuados para cultivar azúcar, café o tabaco; bienes cuya demanda internacional experimentó un fuerte aumento desde finales del Setecientos, principalmente en el caso del azúcar. En todo este engranaje, es incuestionable la importancia que tuvo el comercio en el crecimiento económico de la Isla a lo largo del XIX. Este capital comercial, procedente en su mayoría del negocio azucarero, ocupó desde finales del XVIII la función central del capital social, dominando prácticamente todas las esferas de la vida económica de la Isla. Así controló y desarrolló el transporte marítimo y terrestre, con objeto de mover toda la producción del país hacia los principales puertos para su exportación, de la misma forma estos comerciantes, mediante la inversión de grandes capitales, controlaron los sistemas de almacenaje y embarque y realizaron inversiones que permitieron controlar la fabricación de embases con vistas a la exportación de los productos del país, especialmente bocoyes, toneles y cajas. ${ }^{8}$

Si unimos todo esto a la liberalización del comercio en 1778, los productos de Cuba y Puerto Rico tuvieron suficientes incentivos para explotar estas ventajas y especializar progresivamente sus economías a favor de abastecer el mercado edulcorante. ${ }^{9}$

No obstante, otro de los rasgos significativos de la época, era la escasez relativa de trabajo ${ }^{10}$, de ahí que consideremos dicho motivo como una de las razones por las que el trasiego de emigrantes hacia la ciudad de Cádiz continuaría sucediéndose.

En otro orden de cosas, teniendo en cuenta la cronología estudiada, las revueltas y levantamientos eran constantes, pues será en esta centuria cuando alcancen mayor brío los deseos independentistas de la isla. Aún así, no sería hasta 1898 cuando cristaliza el proceso emancipador que no hemos considerado oportuno extendernos en el tema, pero si tener en cuenta que la presencia de militares cubanos en la ciudad de Cádiz, a la luz de los padrones analizados, se reduciría considerablemente a partir de los años 30 del XIX.

Para concluir este epígrafe abordaremos a grosso modo la cuestión de la emigración europea a la isla, elemento también característico de la sociedad cubana del XIX, tratando de establecer una serie de rasgos característicos acerca de la emigración española vinculada al mundo mercantil y del comercio.

Sabemos por fuentes documentales y oficiales, que la apertura de 12 puertos peninsulares y otros 20 en las colonias, tuvo como consecuencia inevitable un notable crecimiento del comercio, por lo que aumenta el número de barcos que se envían a América, y por tanto, es también mayor el número de emigrantes que se aventuran a cruzar el Atlántico. Fundamentalmente, el contingente migratorio más concurrido será el de los comerciantes, ante la relativa facilidad que proporcionaba la Ley de Libre Comercio a sus negocios mercantiles.

Podemos afirmar que el número de comerciantes entre 1765 y 1824, aumenta a consecuencia directa del Reglamento de Libre Comercio entre España y América.

En este grupo mayoritario de comerciantes podemos hacer una doble distinción:

1) el comerciante propiamente dicho, dedicado a llevar y traer mercancías, inscribiéndose como tal para solicitar su licencia de embarque

2) el comerciante en potencia, el individuo que es reclamado por algún pariente ya establecido en América, que oficialmente no se inscribe como tal, pero que en e motivo del viaje especifica que es reclamado para ayudar a algún pariente en tareas vinculadas al comercio. Al parecer estos individuos sí se quedaran en América, formando parte de la sociedad americana, principalmente la aristocracia comercial que será la que domine el comercio colonial.

\footnotetext{
8 MÁRQUEZ MACÍAS, Rosario: “Comercio e inmigración: los comerciantes españoles en la Habana, 1833-40”. En El sistema Atlántico español (siglos XVII- XIX). Madrid Eds. C. Martínez Shaw y J.M. Oliva Melgar., 2005. pp. 351- 371.

9 MÁRQUEZ MACÍAS, Rosario: "La Habana en el siglo XIX. Una visión a través de la emigración. En Revista de Historia Ubi Sunt. Asociación Cultural Ubi Sunt? Los movimientos migratorios de ayer y de hoy. Año XI. $2^{\circ}$ Trimestre. $\mathrm{N}^{\circ} 23$. Ediciones Mayi. Cádiz. 2008.

10 SANTA MARÍA GARCÍA, Alejandro y GARCÍA ALVAREZ, Antonio: Economía y colonia. La economía cubana y la relación con España, 1765- 1902. Madrid. CSIC. Instituto de Historia. 2004.
} 
Como botón de muestra acompañamos este epígrafe del llamado "comerciante en potencia" una carta- reclamo extraída de la obra de la profesora María Dolores Pérez Murillo; "Cartas de emigrantes escritas desde Cuba". Estudio de las mentalidades y valores en el siglo XIX. ${ }^{11}$

Carta de Juan Lázaro Mansera a D. Francisco de Torres. La Habana, a 6 de agosto de 1817. (A.G.I. Ultramar, 336)

El reclamante, comerciante habanero, dice haber escrito a su hermana Inés al pueblo gaditano de Bornos, para que ésta le envíe a dos de sus nietos. La carta a Inés no aparece en la documentación; sin embargo contamos con el testimonio epistolar que Juan Lázaro Mansera dirige a su amigo, Francisco de Torres, comerciante gaditano. En la referida carta se reclama a Jerónimo y a Alonso Pérez Aguilar Mansera Barrios, naturales de Bornos (Cádiz), para que ayuden a su tío abuelo en el comercio de la Habana y también para que se instruyan en la actividad comercial:

"Estimado amigo: con esta ocasión y con fecha 25 de julio escribo a Bornos a mi hermana doña Inés y le digo que me envíe a uno ó a dos de sus nietos, y le prevengo que los ponga en la casa de usted y a su orden, sin más que ella les saque o mande sacar las fés de bautismo de los dichos, que los autorice como es de costumbre, y el gasto de dichos papeles también se lo pida a usted, en cuya virtud, luego que sean (estén) en su casa, quiero que usted les compre seis mudas de ropa blanca a cada uno, y dos casacas de paño de diferentes colores y también para la mar dos chaquetas y dos pantalones, un baúl, un cobertor, y dos almohadas a cada uno, cuidándolos de la comida, y el gasto todo corre por mi cuenta.

También quiero que traigan su licencia y que si puede ser vengan en buque de guerra, bien sea con el contramaestre o piloto de la embarcación, esto lo dejo a su arbitrio, como que tiene algún conocimiento de diferentes sujetos de dichas clases, con el fin de que vengan con conocidos y tengamos algún alivio en el pasaje, y por supuesto todo corre de mi cuenta, y siendo esto así, luego que salga de ésta para ésa alguna fragata de guerra, le enviaré dinero suficiente, pues las letras de cambio aquí en el día no se hallan, y por tanto, sírvale a usted de gobierno de tener a mi orden sin darle otro destino más que en mi particular los 51 pesos fuertes........

\section{Juan Lázaro Mansera"}

Esta carta presenta sumo valor etnográfico acerca del digno ajuar que debe acompañar a todo, el que con suficiente decoro, deba emigrar hacia América. Existe una monomanía del comerciante español, andaluz sobre todo, establecido en la Habana, a que sus familiares y protegidos, si emprenden la ardua tarea de cruzar el Atlántico, jamás deben mostrar atisbo de origen humilde o situación miserable. Hay por tanto, un culto a la "moral de la apariencia".

Vemos pues que esta figura del comerciante va haciéndose cada vez más numerosa en América, por lo que podemos afirmar que este número aumenta no solo por las licencias en las que aparecen inscritos sino porque estos a su vez van creando un germen de futuros comerciantes, constituyendo con el tiempo la sociedad mercantil de la economía cubana colonial e independentista, y a raíz del libre comercio fueron aumentando en número, haciéndose entre España y América el intercambio de bienes y de personas más abundante tras la promulgación del mismo.

\section{Vínculos humanos entre ambas orillas del Atlántico a través de datos procedentes de los padrones del Archivo Histórico Municipal gaditano ${ }^{12}$}

Una vez analizados los datos extraídos de los libros de empadronamiento del Archivo Histórico Municipal de la ciudad, clasificamos una pequeña muestra de 150 individuos en un período cronológico

\footnotetext{
11 PÉREZ MURILLO, M ${ }^{\mathrm{a}}$ Dolores: Cartas de emigrantes escritas desde Cuba. Estudio de las mentalidades y valores en el siglo XIX. Cádiz-Sevilla. Edit. Aconcagua, Colección "La otra América". 1999. p. 57, carta número 23.

12 PADRONES PROCEDENTES DEL ARCHIVO HISTORICO MUNICIPAL DE CADIZ:

- Padrón General de la Parroquia del Rosario de 1813.

- Padrón General de la Parroquia de San Antonio de 1813.

- Padrón General de la Parroquia de San Lorenzo de 1813.
} 
entre 1804 y 1835, que nos ofreciese una visión general sobre la presencia de cubanos en Cádiz durante los primeros años del XIX.

Comprobamos que la coyuntura constitucional queda marcadamente reflejada en el número de americanos que hacen de Cádiz su lugar de residencia, ya sea temporal o definitiva.

La presencia de políticos es una constante en las listas de empadronamiento. Como dato significativo, registramos el Diputado en Cortes por la ciudad de La Habana: Don Andrés Jáuregui; así como un jugoso grupo de secretarios, abogados y asesores que se trasladan a la ciudad para participar activamente en la labor de la empresa constitucional.

En este caso, las razones de emigración, no irían más allá de las meras exigencias de un traslado temporal para formar parte del nuevo proyecto político.

Mayor atención prestamos al análisis del grueso poblacional cubano que de forma continuada irá llegando a Cádiz en estos años. En las tablas podemos observar una notable presencia de trabajadores e individuos pertenecientes al sector terciario, y muy particularmente al servicio doméstico. Con relación al número de personas censadas, este grupo abarcaría el 36\% de los cubanos empadronados en la ciudad de Cádiz en este primer cuarto del siglo XIX.

Dentro de este sector hemos de distinguir entre la población libre, que sería más de la mitad de los individuos que incluimos en este ámbito del servicio doméstico, y en menor medida, la población esclava.

Los individuos libres son principalmente de raza blanca, en su mayoría mujeres, criadas y asistentas con una edades entre los 20 y los 50 años. Además, resulta interesante destacar que las mujeres empleadas en el servicio doméstico, llegan a Cádiz desde Cuba con una familia al completo; mientras que los individuos que lo hacen solos, en su mayoría comerciantes o rentistas, lo hacen con un servicio domestico fundamentalmente de sexo masculino.

La mano de obra esclava, es fácilmente cuantificable en los padrones por ser estos individuos censados con el dato "de color moreno" o "morenol morena".

El oficio y la labor agrícola es apenas perceptible en Cádiz, por lo que será la modalidad de esclavo urbano la que protagonice con su presencia el grupo de "trabajadores" domésticos privados de libertad. ${ }^{13}$

Entre los esclavos censados hemos querido dar especial relevancia a los niños, pues suponen un número elevado de menores de edad, que desde Cuba, en unos casos solos con sus amos, y en otros con uno de sus progenitores (padre o madre, en ningún caso los dos), son traídos hasta Cádiz.

Suponemos que su capacidad laboral en la ciudad se limitaba considerablemente, y fundamentalmente pretendemos hacer especial hincapié en el valor sentimental que suponía su principal actividad: acompañar y "participar" de los juegos y la vida de los vástagos de la familia a la que estuviesen vinculados.

Lo mismo ocurre con las asistentas y las criadas. Hemos encontrado casos significativos en los que estas esclavas contaban con una edad avanzada, su trabajo en el ámbito doméstico habría mermado considerablemente, y en la mayoría de los casos, su presencia en la familia, crearía ciertos vínculos de afecto que les permitían seguir ejerciendo una labor más decorativa que eficaz.

En este mismo sector terciario, agrupamos también un conjunto de oficios y profesiones que la población cubana continúa ejerciendo en Cádiz; lavanderas, sastres, covachuelistas, cocineros, herreros,

- Padrón General del Barrio de Nuestra Señora de la Candelaria de 1810.

- Padrón General de la Parroquia Matriz de Santa Cruz de 1813.

- Padrón General de la Parroquia de Santiago de 1813.

- Padrón de Vecinos del Barrio de la Viña de 1818.

- Padrón de Vecinos del Barrio de Capuchinos de 1804.

- Padrón General de Vecinos 1805-1809.

- Padrón de Vecinos del Barrio Cruz de la Verdad de 1820.

- Padrón General del Barrio de la Cuna de 1820- 1826.

- Padrón General del Barrio Cruz de la Verdad de 1830.

- Padrones de Extranjeros de 1810. Barrios Nuevo de Santa Cruz y Capuchinos.

- Padrón de Vecinos de 1805- 1823, con entradas y salidas de sus habitantes entre los años 1804 y 1818.

13 PÉREZ MURILLO, M Molores, en su obra: Aspectos sociales y demográficos de la Isla de Cuba durante la primera mitad del siglo XIX. Cádiz. Servicio de Publicaciones de la Universidad de Cádiz. 1988: distingue entre esclavo rural y esclavo urbano. No obstante, esta distinción no tiene posibilidad en el caso gaditano, debido a que el trabajo agrícola es apenas perceptible en la ciudad. 
costureras, zapateras o doradores; y que supondrían un porcentaje de población del 19 al $20 \%$ del conjunto de individuos registrados en los padrones.

Como no destacar la presencia de comerciantes, aunque apreciamos una reducción considerable respecto de años anteriores. Aún así, el contingente americano sigue siendo una constante en la vida cotidiana de Cádiz. Los cubanos llegados hasta la ciudad con asuntos comerciales entre manos, poseen en gran número, algún tipo de establecimiento comercial o mercantil.

En los libros de empadronamiento no se especifica qué tipo de comerciante o a qué comercio se dedicaban estos individuos. Lo que sí podemos destacar es que dentro de la muestra documental recogida, este grupo suponía casi un 15\% del total, y si sumamos a estos el grupo de población cubana que desembarca en Cádiz para, según las propias observaciones escritas en las listas de padrones tales como: "diligencias", "negocios" o "rentas", y que englobarían el 10\% aproximadamente de los individuos censados, deducimos que cerca de un $25 \%$ de la población cubana registrada durante estos años, continúa en Cádiz su labor comercial y de negocios.

Cabe destacar, que un buen número de los comerciantes citados, se incluyen a su vez dentro del grupo de individuos que llegan a la ciudad para resolver asuntos de rentas o negocios, probablemente dueños de algún tipo de inmueble, fundamentalmente propietarios de casas vecinales, administradores de fincas, o dueños de negocios y establecimientos comerciales de los que habrían de hacerse cargo.

La presencia de integrantes del sector militar era una constante en Cádiz. Hemos de tener en cuanta que la ciudad, por el enclave geográfico del que goza y su posición como puerta de América, requería la presencia continuada de tropas. Por otra parte, el contexto convulso de estos primeros años del siglo XIX, incrementó aún más si cabe su presencia; y además, no olvidemos las expediciones que partirán de la ciudad de Cádiz en años anteriores con el objetivo de frenar los brotes independentistas que comenzaban a tener lugar en América.

Las listas de padrones, nos muestran en los primeros años de este siglo XIX, un porcentaje relativamente amplio de militares cubanos en la ciudad de Cádiz, que en relación a la muestra total recogida, supondría un $20 \%$ aproximadamente de tropas residentes en la ciudad a comienzos de este siglo.

De este porcentaje de población van a formar parte militares de todos los rangos y niveles, desde coroneles a capitanes de fragatas y navíos, soldados de infantería, pilotos, oficiales de batalla e integrantes de diferentes tercios de la ciudad.

No obstante, destacaremos que a medida que el tiempo avanza, y la situación permanente de conflictos civiles disminuye, este contingente miliar comienza a decrecer, y observamos que a partir de la década de los 30 fundamentalmente, la presencia de tropas cubanas en la ciudad comienza a reducirse considerablemente.

A modo de conclusión, y volviendo a reiterar la idea comentada al principio del artículo, deducimos que, la presencia americana en la ciudad de Cádiz durante la primera mitad del siglo XIX supone un elemento de investigación mucho más profundo que el realizado hasta el momento. Para ello nos basamos en la presencia constante (de americanos en general, y cubanos en particular), y aún tímidamente consultada, que hemos tenido la oportunidad de analizar en las listas de empadronamiento del Archivo Histórico Municipal de Cádiz.

Y es que a pesar del revés que sufre la actividad mercantil y comercial de la ciudad, del contexto político en que España se encontraba, y principalmente de los brotes independentistas que comenzaban a surgir en el continente americano, creemos, que aún contamos con un contingente de población americana digno de ser tenido en cuenta, y por tanto, de ser estudiado con mayor detenimiento. ${ }^{14}$

Es por ello, que la principal razón de este artículo, ha sido el mero hecho de plantear un estado general de la cuestión, así como poner de manifiesto la viabilidad de un tema que esperamos nos permita, en un futuro sacar a la luz un nuevo capítulo acerca de la vinculación directa entre ambas orillas del Atlántico más allá de la coyuntura constitucional de los primeros años del siglo XIX.

\footnotetext{
14 Hemos de tener en cuenta el contexto político y civil en que nos encontramos, y fundamentalmente los emergentes brotes independentistas que comenzaban a tener lugar en el continente americano. De ahí que se produjese un notable descenso de las transacciones comerciales, y por tanto, del trasiego de mercaderes y comerciantes a la ciudad de Cádiz
} 


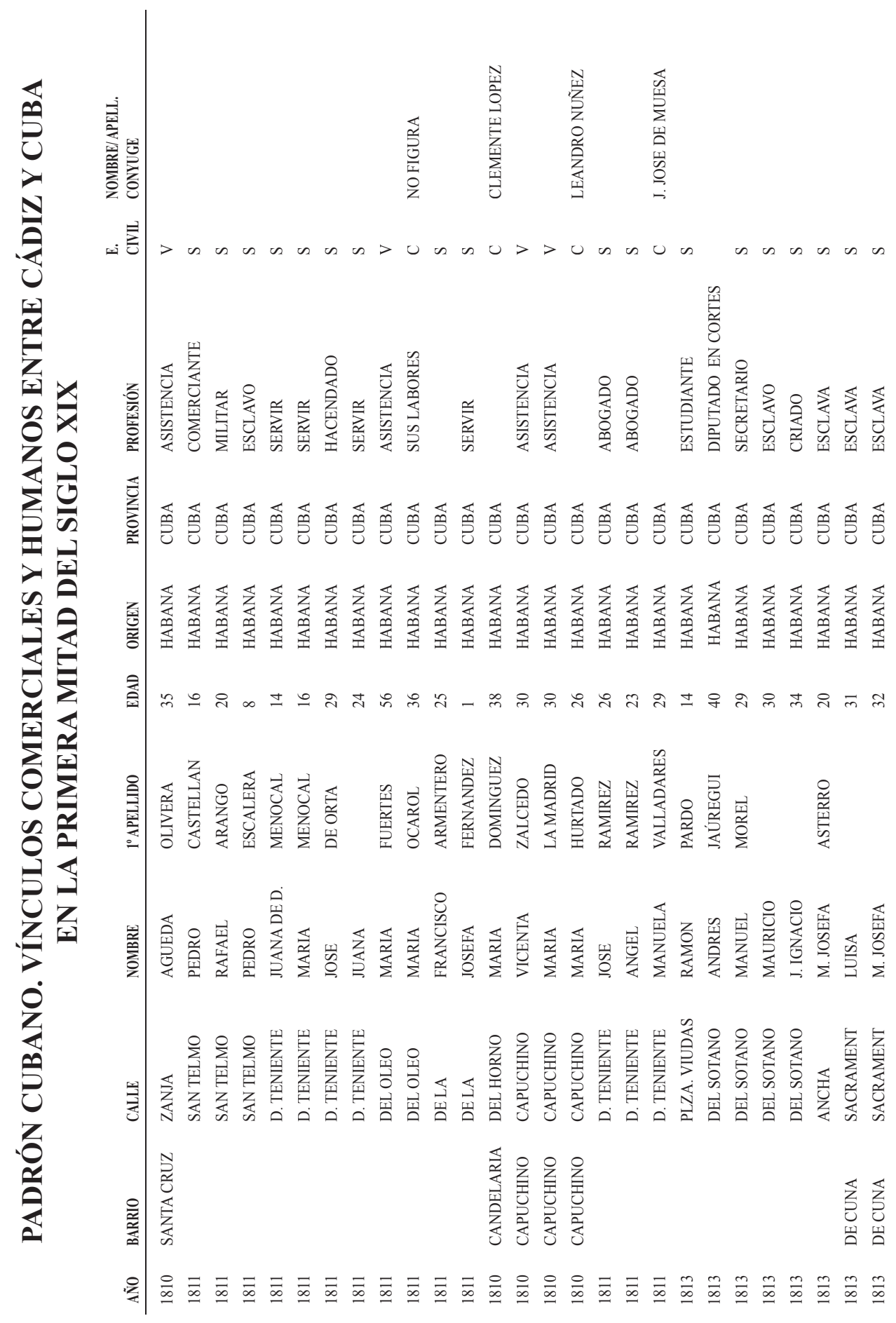




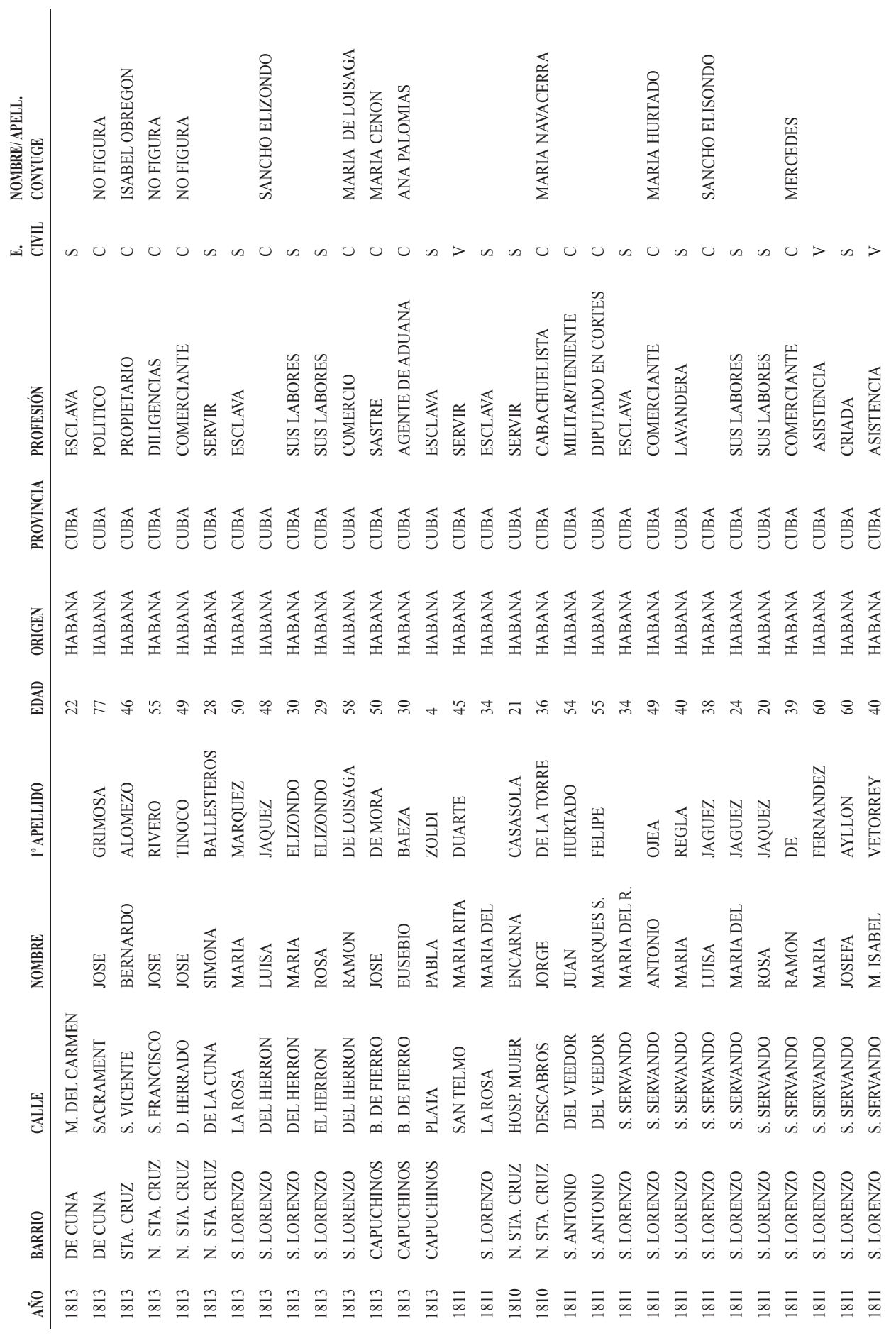




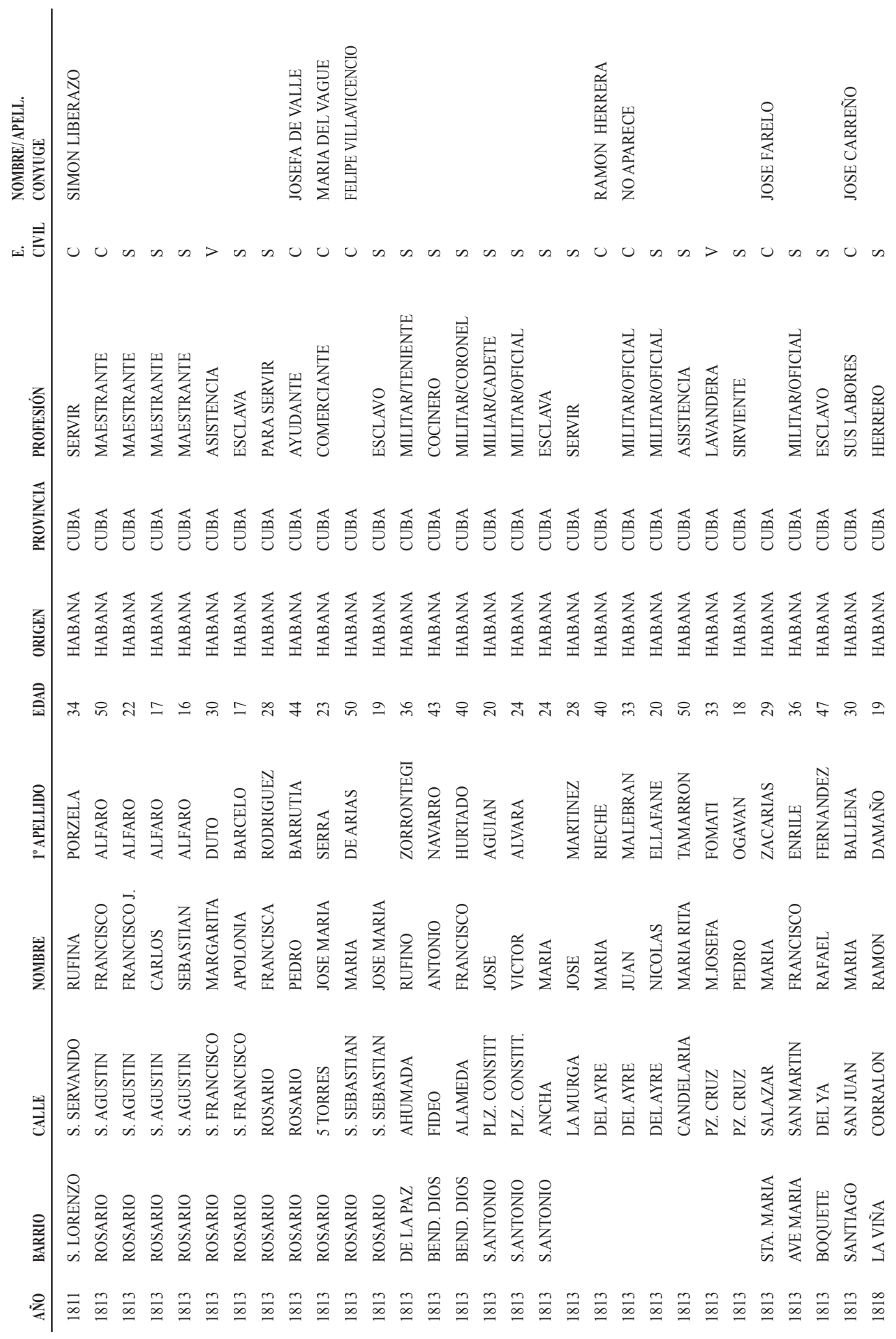




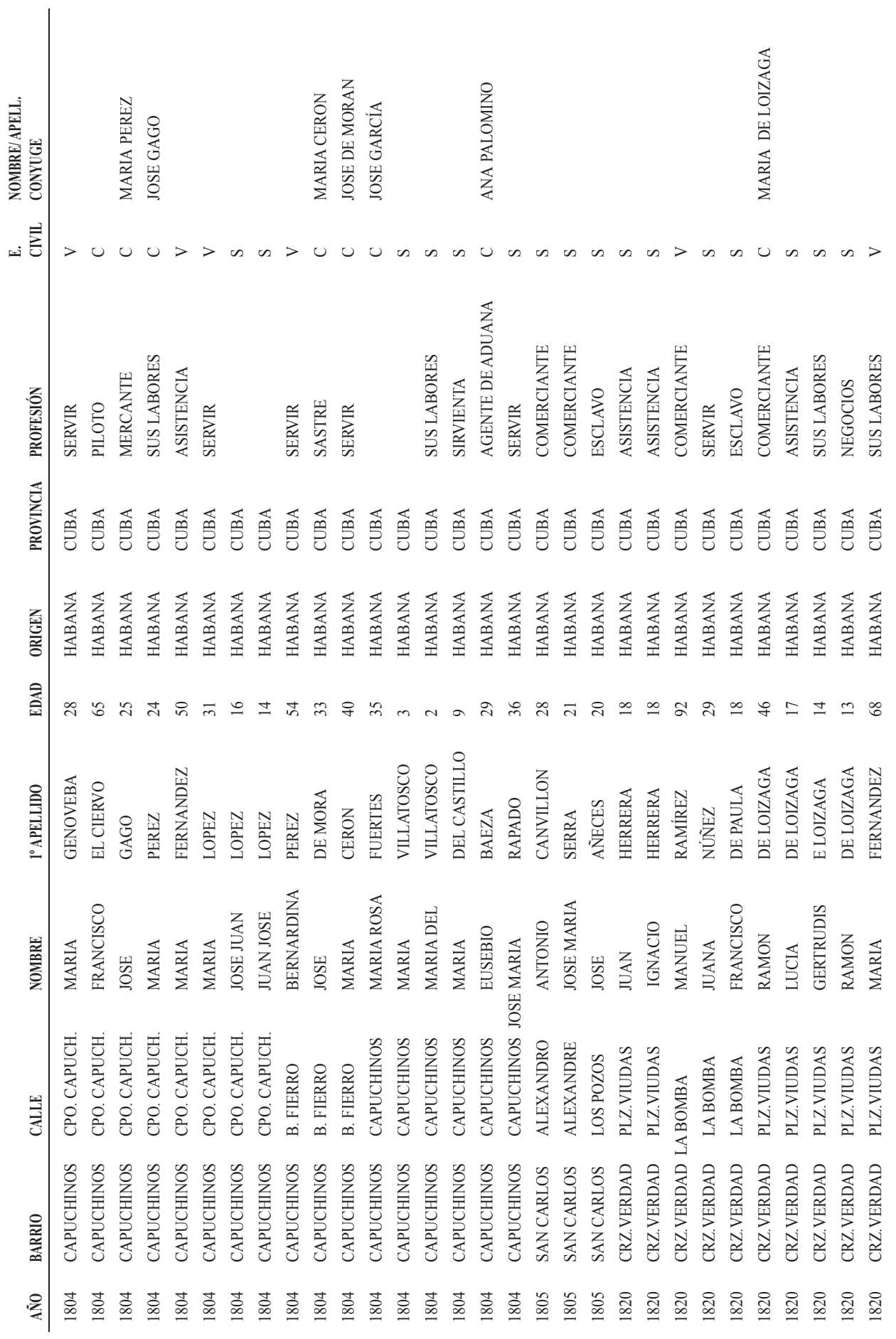




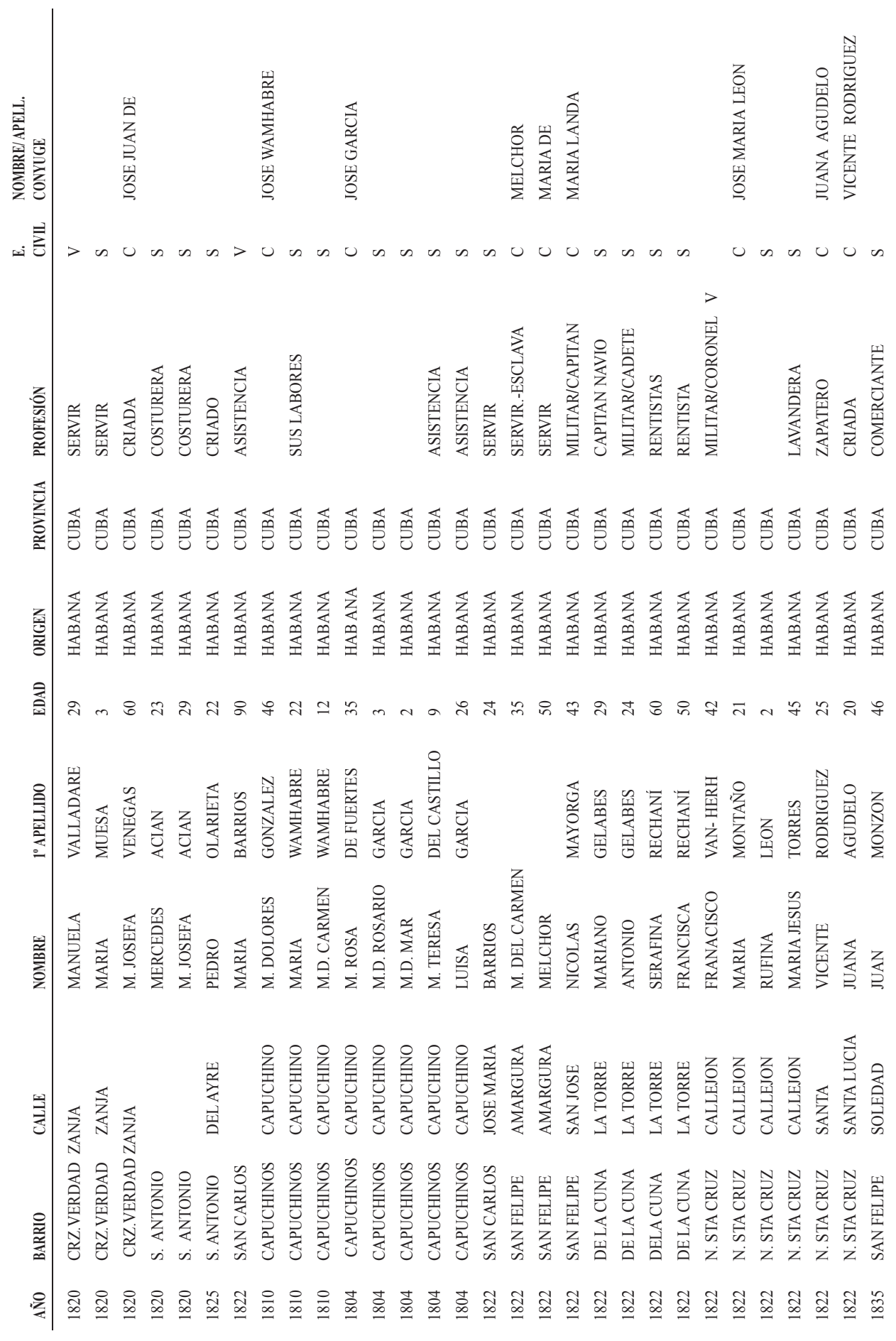




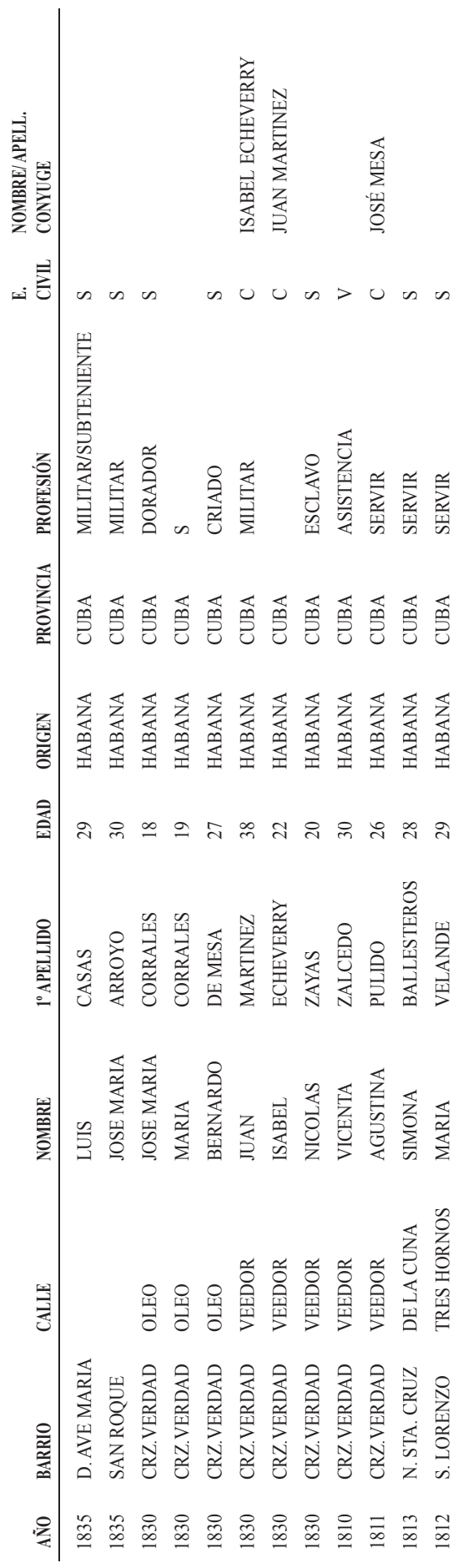

